\title{
PENGARUH PENERAPAN MODEL PROJECT BASED LEARNING MELALUI GOOGLE CLASSROOM TERHADAP HASIL BELAJAR SISWA PADA MATERI LAJU REAKSI
}

\author{
Widia Qholby Jamilla ${ }^{1}$, Lazulva ${ }^{2}$ \\ ${ }^{1,2}$ Fakultas Tarbiyah dan Keguruan, Universitas Islam Negeri Sultan Syarif Kasim Riau \\ Email: widia.qholby14@gmail.com. Phone Number: 082171747307
}

\begin{abstract}
Abstrak
Penerapan kurikulum 2013 yang belum diterapkan secara sempurna menjadi salah satu permasalahan dalam proses pembelajaran. Penelitian ini bertujuan untuk mengetahui pengaruh penerapan Google Classroom pada model pembelajaran Project Based Learning terhadap hasil belajar siswa pada mata pelajaran kimia khususnya materi laju reaksi. Jenis penelitian ini adalah eksperimen semu dengan desain penelitiannya yaitu Posttest Only Control Group Design. Populasi pada penelitian ini yaitu kelas XI MIA MAN 1 Pekanbaru. Adapun sampel diperoleh dengan menggunakan random sampling. Sehingga diperoleh kelas XI MIA 1 (kelas eksperimen) dan XI MIA 2 (kelas kontrol). Teknik pengumpulan data dilakukan dengan wawancara, tes, observasi, dan dokumentasi. Analisis data penelitian ini menggunakan pengujian Independent T-Test. Berdasarkan hasil pengujian Independent T-Test dengan $\alpha=0,05$ diperoleh nilai sig. (2 tailed) sebesar 0.046 ( $\mathrm{H} 0$ ditolak). Penelitian ini menunjukkan bahwa model Project Based Learning berbantu media Google Classroom memberikan hasil belajar yang lebih baik dibandingkan model Project Based Learning yang tidak menggunakan media Google Classroom.

Kata Kunci: Project Based Learning, Google Classroom, Hasil Belajar
\end{abstract}

Abstract

The application of 2013 curriculum which has not been implemented perfectly become a problem in the learning process. This research aimed at knowing the effect of implementing Project Based Learning model with Google Classroom media toward student learning achievement on Chemistry subject, especially Reaction Rate lesson. It was an quasi experiment research with posttest only control group design. The eleventh-grade students of MIA were the population of this research. Random sampling was used in this research, and it was obtained the eleventh-grade students of MIA 1 (experimental group) and MIA 2 (control group). Interview, test, observation, and documentation were the techniques of collecting the data. Analyzing the data was using Independent $t$-test. Based on the results of Independent $t$-test with $\alpha=0.05$, it was obtained the cognitive score of sig. (2 tailed) 0.046 ( $\mathrm{HO}$ was rejected). It showed that Project Based Learning model with Google Classroom media facilitated better learning achievement than the model without the use of Google Classroom media.

Keywords: $\quad$ Project Based Learning, Google Classroom, Learning Achievement

\section{Pendahuluan}

Perkembangan pendidikan tidak bisa terlepas dari perkembangan kurikulum. Sampai saat ini Indonesia telah mengalami sebelas kali perubahan kurikulum yang dapat dikelompokkan menjadi Kurikulum Rencana Pelajaran (1947-1968), Kurikulum Berbasis Tujuan (1975-1984), Kurikulum Berbasis Kompetensi dan KTSP (2004/2006) dan yang terakhir adalah Kurikulum 2013. Kurikulum 2013 adalah kurikulum yang sedang diterapkan di Indonesia saat ini setelah Kurikulum Tingkat Satuan Pendidikan (KTSP). (Addin \& Ariani, 2014) Namun kurikulum yang diterapkan saat ini sudah mengalami 
revisi dalam hal jenis pembelajaran, tujuan pembelajaran, sistem penilaian, kompetensi inti, dan standar kompetensi lulusan.

Kurikulum ini menempatkan siswa sebagai pusat pembelajaran (Student Centered). Proses pembelajaran pada satuan pendidikan diselenggarakan secara interaktif, inspiratif, menyenangkan, menantang, memotivasi siswa untuk berpartisipasi aktif, serta memberikan ruang yang cukup bagi prakarsa, kreativitas, dan kemandirian sesuai dengan bakat, minat, dan perkembangan fisik serta psikologis siswa. Selama proses pembelajaran tersebut, guru menjadi fasilitor agar siswa dapat terlibat secara aktif dan memenuhi standar kompetensi yang ditetapkan dalam kurikulum.(desnylasari et al., 2016)

Adapun model Project Based Learning merupakan salah satu model yang disarankan dan diterapkan dalam pembelajaran kimia pada kurikulum 2013. Model Project Based Learning ini merupakan proyek-proyek yang menghendaki siswa untuk: (1) memecahkan masalah nyata dan isu-isu yang memiliki kepentingan untuk orang lain, (2) secara aktif terlibat dalam pembelajaran dan memilih hal-hal penting selama proyek, (3) menunjukkan secara nyata bahwa mereka telah belajar konsep-konsep kunci dan keterampilan. Proyek memberikan kesempatan bagi siswa untuk menghasilkan bukti yang dapat diamati bahwa mereka telah menguasai standar kurikuler tetap karena mereka menerapkan pembelajaran dan memecahkan masalahnya sendiri. Proyek dan pameran juga memberikan bukti yang luas dari proses kerja dan pembelajaran yang berlangsung sendiri. (Addin \& Ariani, 2014)

Permasalahan kegiatan pembelajaran juga terjadi di MAN 1 Pekanbaru, khususnya pada mata pelajaran kimia. berdasarkan hasil observasi, siswa di MAN 1 Pekanbaru masih jarang terlibat dalam pembelajaran khususnya dalam pelajaran kimia. Guru masih menjadi pusat sedangkan siswa hanya mendengarkan guru berceramah di depan kelas. Hal ini disebabkan karena penerapan model pembelajaran yang memang pada dasarnya kurang melibatkan siswa. Selain itu, siswa juga didapati sering bermain game di handphone androidnya saat belajar, sehingga siswa tidak fokus dengan materi yang disampaikan oleh guru.

Jika dilihat dari hasil belajar siswa khususnya materi laju reaksi pada tahun ajaran sebelumnya, hasil belajar siswa kelas XI yaitu ulangan harian laju reaksi siswa tergolong rendah atau banyak yang belum mencampai kriteria ketuntasan minimal (KKM). Adapan siswa yang belum mencapai KKM sebesar $70 \%$ dengan nilai KKM kimia adalah 80.

Apabila di lihat dari hasil wawancara dengan salah satu guru kimia di MAN 1 Pekanbaru, model Project Based Learning belum diterapkan terutama pada materi laju reaksi. Selain model pembelajaran, ternyata penggunaan media di MAN 1 Pekanbaru masih minim, khususnya media elektronik atau media yang memanfaatkan internet. Siswa di MAN 1 juga tergolong masih kurang disiplin dalam hal belajar.t 
Berdasarkan permasalahan yang dijabarkan di atas, menyebabkan kurang maksimalnya siswa dalam menyerap materi pembelajaran dan pada akhirnya menyebabkan hasil belajar kimia di kelas XI juga masih rendah. Melihat kondisi ini, peneliti berupaya menerapkan model Project Based Learning untuk menerapkan pembelajaran yang sesuai dengan kurikulum 2013 sehingga siswa bisa lebih aktif dalam belajar. Peneliti juga akan menggunakan Google Classroom untuk dijadikan media dalam proses pembelajaran, sehingga penggunaan handphone saat belajar bisa teralihkan menjadi bermanfaat. Diharapkan dengan menerapkan Google Classroom, Google Classroom benar-benar mampu menjadi fasilisator untuk siswa dalam hal belajar. Seingga siswa bisa mendapatkan hasil belajar yang lebih baik.

Berdasarkan masalah-masalah yang ada di MAN 1 Pekanbaru tersebut, peneliti melakukan penelitian dengan judul "Penerapan Model Project Based LearningMelalui Media Google Classroom terhadap Hasil Belajar Siswa pada Materi Laju Reaksi di MAN 1 Pekanbaru"

\section{Metode}

Penelitian dilakukan di MAN 1 Pekanbaru kelas XI MIA pada semester ganjil tahun ajaran 2018/2019. Pengambilan sampel dipilih secara random dengan melakukan uji homogenitas terlebih dahulu. Uji homogenitas dilakukan dengan tujuan apabila diperoleh pengaruh dalam hasil penelitian, pengaruh yang diperoleh bukan karena perbedaan yang dimiliki kelas tersebut melainkan karena perlakuan yang diberikan oleh peneliti.

Jenis penelitian ini berupa eksperimen semu. Desain penelitian yang digunakan adalah posttest only control group design. Penelitian ini terbagi menjadi dua kelompok subjek penelitian yaitu kelompok eksperimen yang diberikan suatu perlakuan yaitu pembelajaran kimia dengan menggunakan model pembelejaran Project Based Learning berbantu Google Classroom dan kelompok kontrol dengan menggunakan model pembelajaran Project Based Learning tanpa Google Classroom.

Data yang dibutuhkan pada penelitian adalah hasil belajar siswa khususnya pada ranah kognitif. Teknik pengumpulan data yang dilakukan baik sebelum ataupun saat penelitian diantaranya, wawancara, tes (uji homogenitas dan posttest), observasi, dan dokumentasi. Adapun untuk data hasil belajarnya diambil dari nilai posttest siswa berupa soal objektif.

Teknik analisis data yang dilakukan selama penelitian salah satunya adalah uji coba instrumen yaitu uji validitas, reliabilitas, tingkat kesukaran, dan uji daya pembeda. Selain uji coba instrumen, dilakukan juga analisis data penelitian yaitu uji normalitas (Shapiro Wilk), uji homogenitas menggunakan uji barlett, uji hipotesis menggunakan T-test Independent Sample. Semua uji tersebut dilakukan menggunakan aplikasi SPSS versi 25.0. 
Bagan alur penelitian yang dilakukan digambarkan pada Gambar 1.

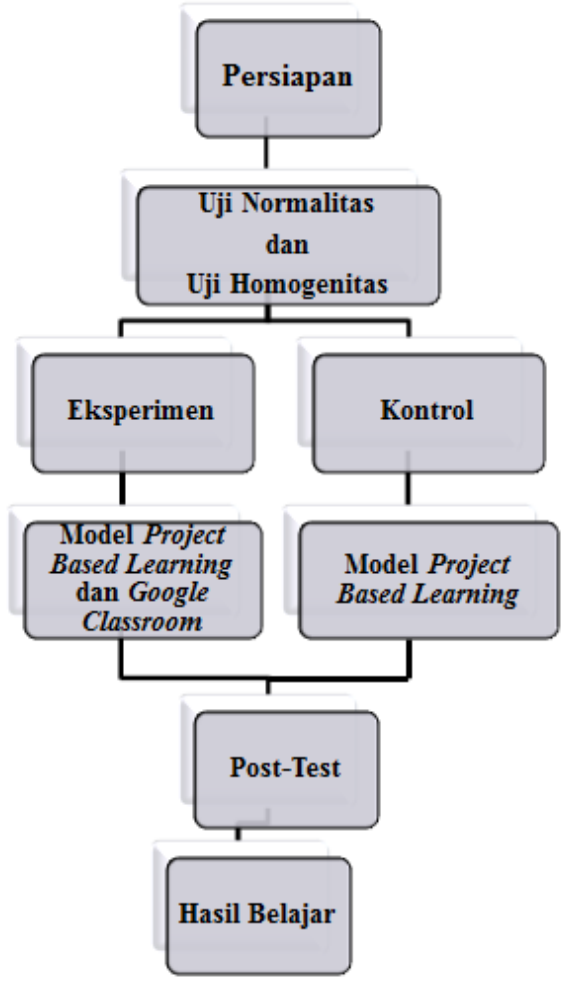

Gambar 1. Alur Penelitian

\section{Hasil dan Pembahasan}

Tujuan penelitian ini adalah untuk mengetahui pengaruh penerapan model Project Based Learning berbantu media Google Classroom terhadap hasil belajar siswa pada materi laju reaksi. Hasil belajar diwakili oleh hasil posttest masing-masing siswa. Setelah dilakukan pembelajaran dengan menerapkan model Project Based Learning berbantu media Google Classroom, peneliti memberikan posttest. Posttest yang diberikan kepada siswa sebelumnya sudah di validasi terlebih dahulu. Sebanyak 30 soal yang tersedia, telah diperoleh 22 soal yang valid (Tabel 1). Sebanyak 22 soal tersebut akan dipilih 20 soal berdasarkan tingkat kesukaran dengan perbandingan soal 3-5-2 (Tabel 2). Sedangkan hasil posttest untuk rata-rata setiap kelas dapat dilihat pada gambar 2. 
Tabel 1. Hasil validitas soal

\begin{tabular}{|c|c|c|c|c|}
\hline No & Kriteria & Nomor Soal & Jumlah & $\begin{array}{l}\text { Persenta } \\
\text { se }\end{array}$ \\
\hline 1 & Valid & $\begin{array}{l}1,2,3,4,6,7,8,9,10,11 \\
12,13,14,16,18,19,20 \\
, 21,22,24,26,30\end{array}$ & 22 & $73,33 \%$ \\
\hline 2 & $\begin{array}{l}\text { Tidak } \\
\text { Valid }\end{array}$ & $\begin{array}{l}5,15,17,23,25,27,28 \\
29\end{array}$ & 8 & $26,67 \%$ \\
\hline \multicolumn{3}{|c|}{ Jumlah } & 30 & $100 \%$ \\
\hline
\end{tabular}

Tabel 2. Tingkat kesukaran soal

\begin{tabular}{lllll}
\hline $\begin{array}{llll}\text { No } \\
\dot{2}\end{array}$ & Kriteria & Nomor Soal & Jumlah & $\begin{array}{l}\text { Persentas } \\
\text { e }\end{array}$ \\
\hline 1 & Mudah & $8,9,13,14,20,21$ & 6 & $30 \%$ \\
2 & Sedan & $1,2,3,7,10,12,16,19,2$ & 10 & $50 \%$ \\
3 & S & 6,30 & 10 & $20 \%$ \\
\hline \multicolumn{7}{l}{ Jumlah } & $4,6,22,23$ & 4 & $100 \%$ \\
\hline
\end{tabular}

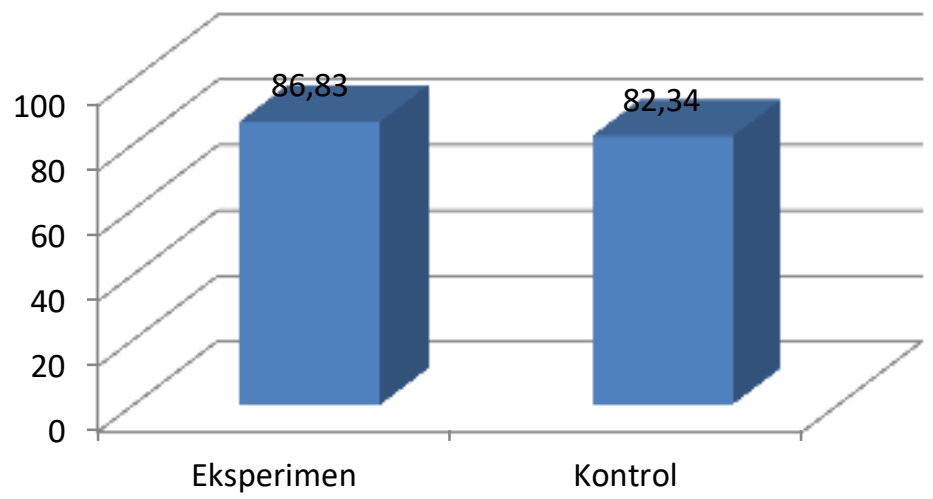

Gambar 2. Rata-rata nilai posttest

Hasil posttest yang diperoleh selanjutnya dilakukan uji hipotesis. Namun sebelum uji hipotesis dilakukan, ada uji prasyarat yang harus dilakukan terlebih dahulu yaitu uji homogenitas dan uji normalitas. Nili uji normalitas yang diperoleh adalah 0,939 untuk kelas eksperimen dan 0,946 untuk kelas kontrol dengan syarat nilai yang diperoleh $>0,05$ maka data yang dieroleh berdistribusi normal. Sedagkan hasil uji homogenitasnya diperoleh nilai sgnifikan sebesar 0,567 yang artinya $>0,05$ maka data 
bersifat homogen. Kemudian dilakukan uji hipotesis dengan cara independent $T$-test dan syarat nilai signifikan $>0,05$ maka bisa diartikan tidak ada pengaruh. Adapun nilai signifikan yang diperoleh adalah $0,046\left(\mathrm{H}_{0}<0,05\right)$ maka mempunya arti bahwa $\mathrm{H}_{0}$ ditolak atau mempunyai pengaruh.

Berdasarkan teori yang dijelaskan oleh Made Wena salah 1 keuntungan Project Based Learning adalah Improved Library Research Skills yaitu keterampilan siswa untuk mencari dan mendapatkan informasi akan meningkat. (Wena, 2011)

Adapun teori ini sesuai dengan penelitian yang dilakukan oleh Anjar Aji Saputro yaitu Hasil belajar pada ranah kognitif dapat meningkat dikarenakan model Project Based Learning merupakan model pembelajaran yang efektif untuk pembelajaran teknik mikroprosesor. Siswa diharapkan dapat mencari informasi sebanyak mungkin secara mandiri. Informasi dapat diperoleh dari bertanya kepada guru atau teman, mencari pada sumber belajar seperti internet dan labsheet, dan lain-lain. Tidak dibatasinya siswa dalam mencari informasi merupakan modal utama agar siswa dapat meningkatkan hasil belajar ranah kognitif.(Saputro, 2014) Keuntungan yang diperoleh dalam penerapan Project Based Learning ini jika didukung oleh Google Classroom bisa membuat siswa lebih menghemat waktunya dalam mencari informasi atau siswa bisa mempunyai informasi yang lebih banyak lagi karena guru juga sudah memberikan materi yang berkaitan dengan proyek seperti yang diungkapkan oleh Willy Prastiyo yaitu dengan menggunakan Google Classroom guru bisa membagikan materi, pengumuman, kuis atau soal, tugas, penilaian tugas untuk siswa.(Prastyo et al., 2018) Sesuai dengan penelitian yang dilakukan oleh Anjar Aji Saputro bahwa ranah kognitif siswa dapat ditingkatkan lagi dengan memanfaatkan media pembelajaran yang bervariasi. Variasi media pembelajaran meliputi penggunaan komputer untuk menyelesaikan masalah yaitu dengan simulasi, pemberian materi menggunakan media interaktif, pemberian apersepsi dan contoh-contoh proyek menggunakan video pembelajaran, dan lainlain.(Saputro, 2014)

Tingginya kelas eksperimen dalam nilai kognitif disebabkan oleh penerapan Google Classroom, karena selama menerapkan Google Classroom belajar siswa lebih terarah dan teratur karena adanya persiapan sebelum belajar atau pengulangan materi sebelumnya bersama guru dibandingkan kelas kontrol yang tidak menggunakan Google Classroom. Sehingga pengulangan materi ini mampu meningkatkan kemampuan kognitif siswa pada aspek kognitif $\mathrm{C} 1$ yaitu mengingat, $\mathrm{C} 2$ yaitu memahami, dan C4 yaitu menganalisis. Diantara ketiga aspek tersebut, aspek yang paling tinggi diperoleh oleh siswa adalah aspek $\mathrm{C} 1$ yaitu mengingat. Hal ini terjadi karena pengulangan materi yang dilakukan mampu membuat ingatan siswa lebih baik dibandingkan dengan kelas yang tidak melakukan pengulangan materi. Meskipun kelas eksperimen memperoleh rata-rata nilai lebih tinggi dibandingkan kelas kontrol, terdapat beberapa siswa yang mendapatkan nilai rendah. Nilai rendah yang diperoleh ini, disebabkan oleh ketidakhadiran mereka di Google Classroom. Sehingga mereka jarang mengulangi 
materi dan itu berdampak kepada nilai mereka. Berdasarkan penelitian yang dilakukan oleh Suci Pratiwi Agustin diperoleh hasil bahwa Pembelajaran Blended Learning berbantuan Google Classroom berpengaruh terhadap hasil belajar rata-rata tiap siswa kelas eksperimen dengan perolehan $\mathrm{N}$-gain sebesar 0.56 dan berpengaruh terhadap hasil belajar rata-rata per aspek kognitif dengan perolehan $\mathrm{N}$-gain sebesar 0.45 . (Pratiwi, 2019)

\section{Kesimpulan}

Berdasarkan hasil penelitian dan pembahasan pada penelitian ini, maka diperoleh beberapa kesimpulan bahwa, pada hasil belajar kimia ranah kognitif, ada perbedaan nilai yang signifikan anatara kelas eksperimen dan kelas kontrol. Dimana rata-rata nilai kelas eksperimen yaitu 86,83 lebih tinggi dibandingkan kelas kontrol yaitu 82,34. Dengan demikian bisa disimpulkan bahwa model Project Based Learning berbantu media Google Classroom memberikan nilai yang lebih baik dalam ranah kognitif dibandingkan model Project Based Learning yang tidak menggunakan media Google Classroom.

\section{Daftar Referensi}

Addiin, I \& Ariani, S.R.D. (2014). Penerapan model pembelajaran Project Based Learning pada materi pokok larutan asam dan basa di kelas XI IPA 1 SMA Negeri 2 Karangayar tahun ajaran 2013/2014. Jurnal Pendidikan Kimia, 3(4),7-16

Desnylasari, E, Mulyani, S \& Mulyani, B. (2016). Pengaruh model pembelajaran Project Based Learning dan Problem Based Learning pada materi termokimia terhadap prestasi belajar siswa kelas XI SMA Negeri 1 Karangayar. Jurnal Pendidikan Kimia, 5(1),134-142

Prastiyo, W, Djohar, A \& Purnawan. (2018). Development of youtube integrated Google Classroom based e-learning media for the light-weight vehicle engineering vocational high school. Jurnal Pendidikan Vokasi, 8(1), 53-56

Pratiwi, S. (2019). Pengaruh blended learning berbantuan Google Classroom terhadap hasil belajar siswa SMA pada konsep gerak lurus. Universitas Islam Negeri Syarif Hidayatullah, Jakarta

Saputro, A.A. (2014). Efektivitas model Project Based Learning pada mata pelajaran teknik mikroprosesor di SMKN 2 Yogyakarta. Universitas Negeri Yogyakarta, Yogyakarta

Wena, M. (2011). Strategi pembelajaran inovatif kontomporer. Jakarta: Bumi Aksara 